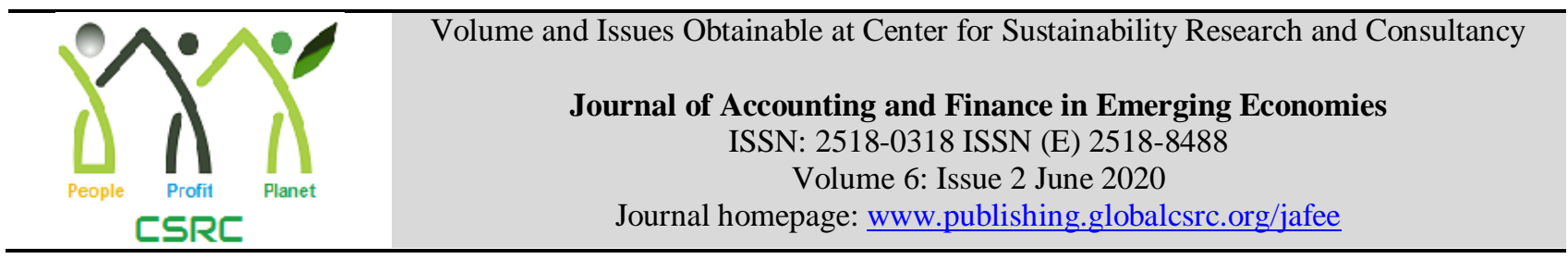

\title{
Perceived Risk Factors Affect Intention to Use FinTech
}

\section{${ }^{1}$ Ooi Chee Keong, ${ }^{2}$ Tang Kin Leong, ${ }^{3}$ Chong Jia Bao}

${ }^{1,2 \& 3}$ Faculty of Accountancy and Management, Universiti Tunku Abdul Rahman, ckooi@utar.edu.my tangk1@utar.edu.my

jiabao0219@hotmail.com

\begin{tabular}{l}
\hline ARTICLE DETAILS \\
\hline History \\
Revised format: May 2020 \\
Available Online: June \\
2020
\end{tabular}

Keywords

FinTech, FinTech Usage

Intention, Financial Risk,

Legal Risk, Security Risk,

Operational Risk.

JEL Classification

M1, M14

\begin{abstract}
Objective: Studies show there is a high acceptance of FinTech development in Malaysia. However, the perceived risk factors that hinder a user's intention to use FinTech remains vague. Research on perceived risk is limited, especially the use of FinTech in the context of Malaysia. Therefore, this study aims to narrow the gap in perceived risk factors of FinTech.
\end{abstract}

Methodology: A total of 302 participants participated in the study. Collected data and hypotheses were tested using the method of structural equation modeling.

Results: It is found that three of the four dimensions of financial risk, legal risk and operational risk have a significant negative impact on the intention to use FinTech. The findings found that security risks do not have a significant negative effect on the intention to use FinTech. This result is consistent with the finding that Malaysian consumers' perception of e-payment is not significantly related to perceived security.

Implication: The results help practitioners better conceptualize and reduce risk barriers in preparing for the disruption of FinTech. Practitioners are also advised to pay attention to FinTech's operational skills and system functional performance in FinTech services.

(C) 2020 The authors, under a Creative Commons

Attribution-NonCommercial 4.0

Corresponding author's email address: kinleong.tang@gmail.com

Recommended citation: Keong, O. C., Leong, T. K., Bio, C. J. (2020). Perceived Risk Factors Affect Intention To Use FinTech. Journal of Accounting and Finance in Emerging Economies, 6(2), 453-463

\section{Introduction}

FinTech is the combination of "finance" and "technology", which has aroused great interest in the market in recent years. EY (2019) refer to FinTech is "an organisation that combines innovative business models and technologies to realise, enhance, and disrupt financial services". In a general sense, FinTech means companies that provide financial software solutions to customers. FinTech companies fall into nine categories, such as financing, asset management, exchange services, insurance, loyalty program, payment, regulatory technology, risk management, and other areas including education and 
training.

A study conducted by EY (2019), found that the adoption rate of global FinTech grew faster than expected, from 52\% in 2017 to $64 \%$ in 2019. At the same time, the global level of FinTech awareness is surprisingly high (computer mobile payment $89 \%$ and a peer-to-peer payment system and non-bank money transfer services 82\%) (EY, 2019). Likewise, the development of Malaysia's electronic payment and online banking technologies has much promoted the development of Malaysia's FinTech innovation and related commercial activities. However, a study conducted by Padmanaban and Soo (2016) found that $82 \%$ of financial institution respondents were concerned about the threat posed by FinTech. Consumers, in turn, worry about the potential perceived risks of using FinTech.

Besides, much of the existing research has focused on the various factors that predict the intention to use FinTech. Limited research has focused on constraints and risk factors that hinder consumers' intention to use FinTech. Therefore, it is necessary to investigate the perceived risk factors influencing the intention of Malaysian consumers to use FinTech.

\section{Literature Review}

FinTech is not only limited to financial services, such as providing financing, create new business models (such as P2P lending and crowdsourcing), but also performs business operations, provides services and delivers products as an alternative to traditional financial institutions (Arner, Barberis, \& Buckley, 2015). In general, FinTech is an innovative and disruptive product and service of modern nonfinancial institutions (Lee \& Teo, 2015; Sweeney, 2017). FinTech also refers to the use of emerging information technologies, including big data, cloud computing and mobile technologies, to improve the quality of services and management efficiency, and expand the field of financial services ( $\mathrm{Hu}, \mathrm{Ding}, \mathrm{Li}$, Chen, \& Yang, 2019). Thus, FinTech can be considered as a technology enabler to provide a better user experience and improve competitiveness in finance.

In this study, the FinTech is defined as the innovation and technology disruption of financial services by non-financial enterprises, with the help of FinTech, customers can participate in a variety of mobile environment services. For example, online payment, fund transfer, loan application, purchase of insurance policies, management of organisational assets and management, stock investment, mobile payment, InsureTech, P2P lending, crowdfunding, cryptocurrency, etc. (Ryu, 2018).

The enormous benefits of FinTech provide a potential opportunity for consumers to gain an environment of amplification and transparency, reduce expenses, eliminate intermediaries, and make financial information more accessible (Zavolokina, Dolata, \& Schwabe, 2016). However, FinTech institutions face both the potential advantages of FinTech and the challenge of overcoming their potential uncertainties or harm to consumers at the same time (Chan, 2015).

Meanwhile, from the consumer's point of view, although FinTech has attracted much attention, the intent to use it is still considered unreliable and uncertain. It is believed that a person who strongly believes in negativity will have a negative attitude towards such behaviour (Ajzen \& Fishbein, 1977). Consumers may be reluctant to use FinTech, mainly because the risks are considerable. These unforeseeable risks of FinTech use may harm customers and thus hinder their use of FinTech. Therefore, this has led to this study on the consumers' perceived risk factors of the use of FinTech.

\subsection{Theory of Reasoned Action (TRA)}

Theory of Reasoned Action (TRA) is widely used to predict human behaviour. The Theory of Reasoned Action (TRA) explains that individual behaviour is driven by behavioural intentions, which is the determinants of an individual's attitude toward behaviour. In short, a person who strongly believes in positive outcomes will have a positive attitude about the behaviour, while a person who strongly believes in negative consequences will have a negative attitude about the behaviour (Ajzen \& Fishbein, 
1977).

According to TRA, one's behavioural intention is influenced by two predictors, attitude and subjective norms (Ajzen \& Fishbein, 1977). Attitude toward behaviour refers to one' evaluation about performing a given behaviour is influenced by the attitude toward the behaviour and social pressure. Attitude refers to the positive or negative feeling when performing a given behaviour (Al-Mamary, Al-nashmi, Hassan, \& Shamsuddin, 2016). The study found that a positive attitude is a prerequisite for adopting new technologies (Hu et al., 2019). Subjective norms are the reflection of social pressure and the individual's perception of others that he/she shall or should not to perform a given behaviour. There is a strong relationship between subjective norms and intention in the consumer's technology adoption perspective.

The objective of this study is to determine the customer's perceived risks factors for the intention to use FinTech. The intention of FinTech usage is controlled by the attitude of FinTech users towards the use of FinTech, which is achieved by applying the theory of Reasoned Action (TRA) to the FinTech environment. It is believed that in addition to selecting services, consumers will also consider accessible services (Kim, Ferrin, \& Rao, 2008). Since consumers may be reluctant to use FinTech due to risk considerations, it is crucial to understand the perceived risk factors when developing and promoting the use of FinTech.

\subsection{Perceived Risk Theory}

Perceived risk theory can be used to understand consumer behaviour. Bauer (1960), as cited by Quintal, Lee, and Soutar (2006), introduced perceived risk and called it the influence that led to the overall perceived value of purchase behaviour. Cunningham (1967), as cited by Ryu (2018) and Mitchell and Nygaard (1999), refers to perceived risk as the deterministic feeling if the result is adversely unfavourable.

According to Ryu (2018), there are six measures of perceived risk, including performance, financial considerations, opportunity or time, safety, social factors and psychological factors. Luo, Li, Zhang, and Shim (2010) put forward that performance, finance, time, psychological, social, privacy and overall risk are the key risk factors in the initial adoption stage of the wireless Internet platform.

\subsection{FinTech Risk Perception}

Perceived risk has different definitions. In the information system context, perceived risk has a negative impact on information technology (IT) or information system service adoption (Ryu, 2018). Perceived risk is a vital factor when consumers considering the use of FinTech. Ryu (2018) refers to the perceived risks is associated with products or services found in the use and innovation adoption study. Perceived risk is the subjective uncertainty that one will "win" or "lose" all or part of the amount of stake (Rich, 2014). Perceived risk is thus defined as "consumers' impression of vulnerability and the conceivable negative consequences associated with the FinTech".

Abramova and Böhme (2016) found in their study that perceived risk has multiple levels, which collectively have a negative impact on the use of bitcoin. Based on Ryu (2018) dimension of perceived risk and FinTech context, this study identified four dimensions of perceived risk factor, namely, security risk, financial risk, legal risk and operational risk, which may affect consumers' FinTech adoption intention. This study regards perceived risk as the obstacle for consumers to use FinTech and discusses that financial risk, legal risk, security risk and operational risk are the main factors hindering the use of FinTech.

\subsection{Financial Risk}

Financial risk refers to the possibility of financial losses in financial transactions conducted by FinTech (Forsythe, Liu, Shannon, \& Gardner, 2006). Previous literature studies on information systems have shown that perceived financial risk is the most critical indicator adopted by network and mobile phone 
users (Ryu, 2018). FinTech's financial losses as explained by Ryu (2018) is the risk brought by the budgetary exchange framework, currency misrepresentation, moral danger, and the risk of additional exchange fees associated with preferred value, which negatively affected the intention to use FinTech. According to Luo et al. (2010), in the field of financial services, financial risks have increased and include the possibility of recurrence of financial losses due to fraud. Therefore, financial risk has a negative impact on FinTech use intention.

H1: Financial risk has a negative effect on FinTech use intention.

\subsection{Legal Risk}

Legal risk refers to the vague legal status and the lack of comprehensive guidelines for FinTech. Bank Negara Malaysia (BNM), for example, has put in place a framework that allows FinTech solutions to be tested in a real-world environment before being brought to market. Elements of the framework include an active stance (protecting data security and privacy) and safeguards (protecting the country's financial system). All FinTech products/services, whether established within or outside Malaysia, must comply with Malaysian laws regulated by BNM Malaysia and Malaysia Securities Commission (SC) (Siaw \& Kow, 2019). Since FinTech is new to the market, the lack of guidelines on FinTech's currency-related misfortunes and security issues has created fear, suspicion and unease among users. Therefore, legal risk is hypothesised has a negative effect on FinTech usage intention.

H2: Legal risk has a negative effect on FinTech use intention.

\subsection{Security Risk}

Luo et al. (2010) defined security risk as a potential loss of control over personal information, such as the use of personal information without consent or permission. Security risk remains a powerful barrier to the use of FinTech due to a lack of confidence in information technology.

In this study, the security risk is characterised as the potential misfortune caused by blackmail or hacker attack on the security system of financial transactions of FinTech companies. Concerning electronic services, the concept of security risk is possible to protect against attacks. This is the primary concern of consumers (Lwin, Wirtz, \& Williams, 2007). Fraud and network intrusion can cause financial misfortune for users as well as ignoring their security (Ryu, 2018). Ryu (2018) argue that the use of FinTech is usually accompanied by higher potential misfortune, such as confidentiality, personal information and trading. It also contributes to the formation of the perceived risk of FinTech usage. Therefore, the security risk is hypothesised has a negative impact on the use of FinTech.

H3: Security risk has a negative effect on FinTech use intention.

\subsection{Operational Risk}

Operational risks are related to performance risks defined by Luo et al. (2010). They refer to operational risk as to the possibility of product failure, or the product not working as it was designed and advertised, thus failing to provide the expected benefits (Luo et al., 2010). Operational risk in FinTech context refers to the possible misfortune caused by defects or failures of internal processes, people and frameworks (Barakat \& Hussainey, 2013). Operational risk is a fundamental concern for users, as many major operational failures hit large financial institutions, leading to extreme currency volatility or the collapse of such institutions (e.g., Lending Club). In the case of the high-risk probability of financial system and operation of FinTech institutions, users will not have the intention to use FinTech. In addition, the lack of operational and rapid response capabilities, framework failures, and lack of internal processes will lead to user scepticism and disappointment, which will lead to the obstacle on the intention to use FinTech. Therefore, this study hypothesises that operational risk has a negative impact on the intention to use FinTech. 
H4: Operational risk has a negative effect on FinTech use intention.

\section{Methodology}

In this study, Malaysians living in Malaysia were selected as the survey respondents, who were over 18 years old and had personal bank accounts to meet the legal age of contractual capacity. The survey will be conducted regardless of gender, race, religion or ethnicity. Self-administered questionnaires are distributed on the website (Google form) with hyperlinks emailed to respondents, including peninsular Malaysia and Sabah and Sarawak.

The construct measurements used in this study were derived from previous studies. Each construct item was measured using five Likert scales, ranging from strongly disagree (1) to strongly agree (5).

\section{Data Analysis and Results}

Data of 302 respondents were collected, and SPSS statistical software version 20 was used for demographic analysis. By using the method of structural equation modelling, the structural model was analysed by using the software of Smart-PLS statistical analysis tool.

\subsection{Sampling and Data Collection}

According to table 2, 302 usability questionnaires were collected, including 147 (48.7\%) for men and $155(51.3 \%)$ for women. $84(27.8 \%)$ people aged 18-24, $101(33.4 \%)$ people aged 25-34, $62(20.5 \%)$ people aged 35-44, and $55(18.2 \%)$ people aged over 45.

In terms of monthly income, 76 respondents $(25.2 \%)$ had a monthly income of less than 2,500 yuan. The next two income groups were RM 2,501-rm 3,500 and RM 3,501-rm 4,500, respectively, with 69 (22.8\%) and 64 (21.2\%). Finally, the income groups of RM 4,501, RM 5,500 and RM 5,500 and above, $42(13.9 \%)$ and $51(16.9 \%)$.

Refer to respondents' education level, and it is composed of three levels. The respondents are mainly undergraduates, accounting for $181(59.9 \%)$. It was followed by $71(23.5 \%)$ primary/secondary school students and $50(16.6 \%)$ graduate students.

Table 1: Demographic profile of participants $(n=302)$

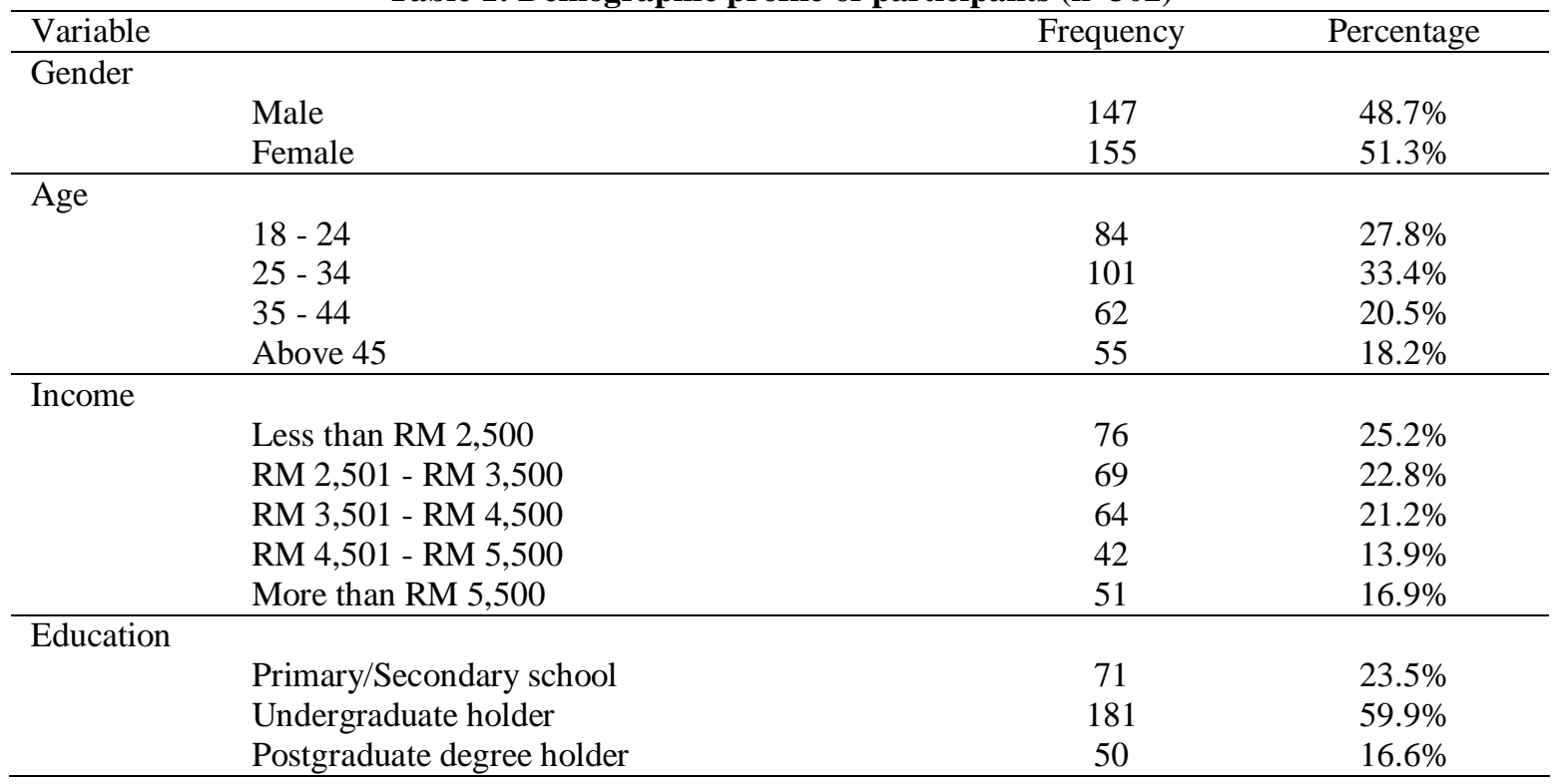




\subsection{Measurement Model Assessment}

\subsubsection{Internal Consistency Reliability and Convergent Validity}

As can be seen from table 2, the results of the measurement assessment model show that all indicators and constructs meet the reflective measurement criteria, that is, the loading of all indicators is greater than 0.738 , the average variance extracted (AVE) value is greater than 0.5 . The composite reliability is higher than 0.70 . In conclusion, the results show that all indicators are reliable, the convergence validity of constructs is achieved, and the internal consistency of data is reached.

Table 2: Measurement Model

\begin{tabular}{ccccc}
\hline Construct & Indicators & Loadings & AVE & CR \\
\hline Financial Risk & FR1 & 0.911 & 0.813 & 0.929 \\
& FR2 & 0.899 & & \\
& FR3 & 0.894 & 0.614 & \\
\hline Intention & IF1 & 0.814 & & \\
& IF2 & 0.796 & 0.928 \\
& IF3 & 0.785 & \\
& IF4 & 0.738 & 0.764 & \\
\hline Legal Risk & LR1 & 0.855 & & \\
& LR2 & 0.877 & & \\
& LR3 & 0.884 & 0.807 & \\
\hline Operational Risk & OR4 & 0.880 & & \\
& OR1 & 0.884 & & \\
& OR2 & 0.909 & 0.759 \\
\hline OR3 & SR1 & 0.902 & & \\
\hline
\end{tabular}

\subsubsection{Discriminant Validity}

According to Fornell \& Larcker (1981), to satisfy discriminant validity, the loading of own constructs in the model should be higher than that of other constructs. Based on this criterion, all constructs in table 3 meet this criterion. Table 4 shows the method of discriminant analysis by comparing cross loads between structures.

Table 3: Discriminant Validity using Fornell and Lacker Criterion

\begin{tabular}{cccccc}
\hline & Financial Risk & Intention & Legal Risk & Operational Risk & Security Risk \\
\hline Financial Risk & 0.902 & & & & \\
\hline Intention & 0.485 & 0.784 & & & \\
\hline Legal Risk & 0.740 & 0.487 & 0.874 & & \\
\hline Operational Risk & 0.660 & 0.480 & 0.683 & 0.898 & 0.871 \\
\hline Security Risk & 0.664 & 0.422 & 0.600 & 0.711 & \\
\hline
\end{tabular}

Table 4: Cross-Loadings

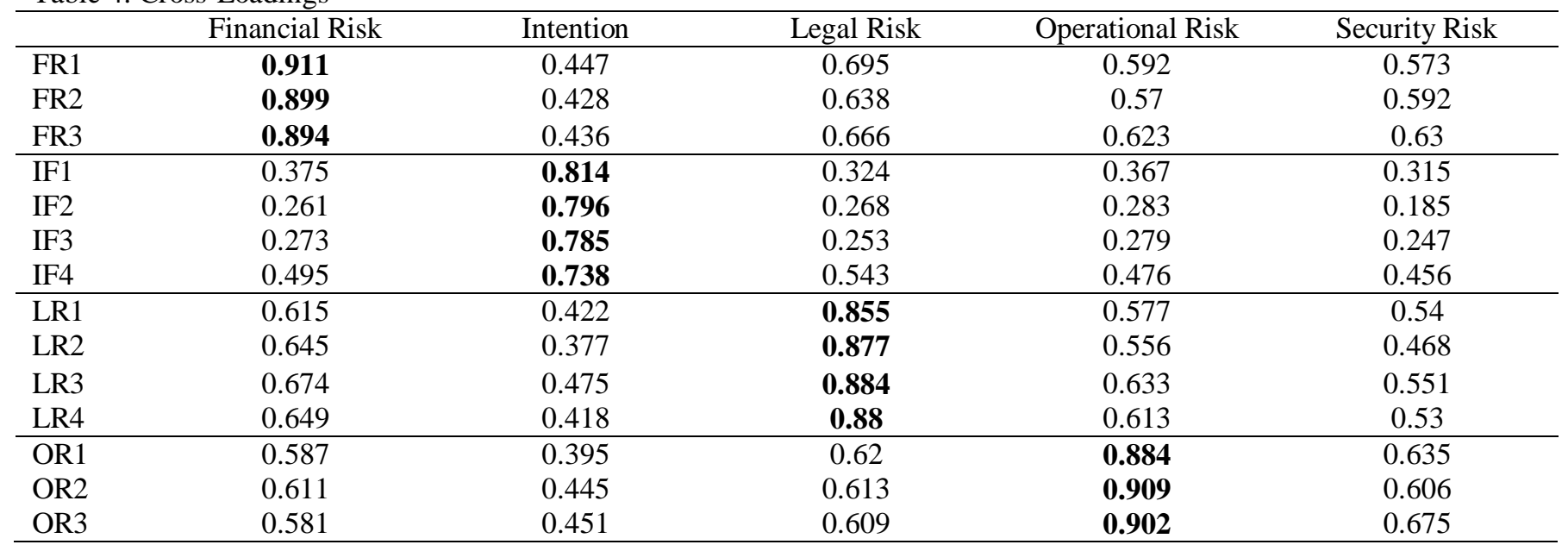




\begin{tabular}{llllll}
\hline SR1 & 0.554 & 0.359 & 0.473 & 0.591 & $\mathbf{0 . 8 6 7}$ \\
SR2 & 0.621 & 0.386 & 0.574 & 0.631 & $\mathbf{0 . 8 8 7}$ \\
SR3 & 0.558 & 0.358 & 0.519 & 0.635 & $\mathbf{0 . 8 5 9}$ \\
\hline
\end{tabular}

Table 5 shows the results of discriminant validity assessed using Heterotrait-Monotrait (HTMT) ratio of correlation criterion. With reference to the obtained values, all the values meet the criterion of HTMT.90 (Palacios, Kaspereit, \& Kienle, 2011) indicating that discriminant validity was confirmed.

Table 5: HTMT Criterion

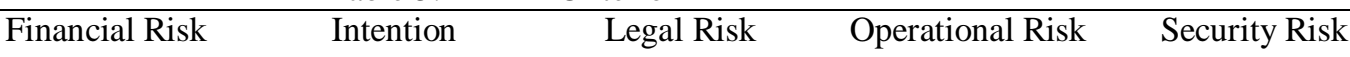

\begin{tabular}{|c|c|c|c|c|}
\hline Financial Risk & & & & \\
\hline Intention & 0.524 & & & \\
\hline Legal Risk & 0.828 & 0.512 & & \\
\hline Operational Risk & 0.747 & 0.525 & 0.766 & \\
\hline Security Risk & 0.768 & 0.461 & 0.686 & 0.825 \\
\hline
\end{tabular}

\subsubsection{Structural Model Assessment}

A bootstrapping procedure with 5000 sub-samples was conducted to examine the structural model and to confirm the established hypotheses.

\subsubsection{Collinearity}

Table 6 shows the variance inflation factor (VIF) value of all constructs in the model. The results indicate that all the constructs' VIF is less than 3, indicating that there is no collinearity problem in the structural model.

Table 6: Variance Inflation Factor (VIF)

\begin{tabular}{lc}
\hline Construct & Intention \\
\hline Intention & 1.000 \\
Financial Risk & 2.696 \\
Legal Risk & 2.595 \\
Operational Risk & 2.595 \\
Security Risk & 2.340 \\
\hline
\end{tabular}

\subsubsection{Assess Path Coefficient}

Bootstrapping procedure of 5000 subsamples was used to examine the path coefficient. The result shows that the R2 of the structural model is 0.295 . The variance of about $30 \%$ of intention to use FinTech can be explained by other exogenous variables such as financial risk, legal risk, security risk and operational risk. However, an evaluation of the effect size of the predictor using Cohen's f2 (Cohen, 1988) showed that all the effect size of all predictors was small (f2 less than 0.02). Lastly, the Blindfolding procedure was used to evaluate the predictive relevance $(\mathrm{Q} 2)$, and the result Q2 0.143 was greater than 0 , indicating that exogenous constructs had predictive relevance with endogenous constructs.

Table 7 summarises the hypothesis testing results, indicates that financial risk (H1), legal risk (H2) and operational risk (H4) have a significantly negative effect on FinTech usage. Meanwhile, security risk found insignificant in the relationship.

Table 7: Hypothesis Testing

\begin{tabular}{cccccccc}
\hline Hypothesis & Relationship & Path coefficient & P-value & t-value & Decision & $\mathrm{f}^{2}$ & $\mathrm{Q}^{2}$ \\
\hline $\mathrm{H} 1$ & 0.184 & 0.019 & 2.068 & Supported & 0.018 & 0.143 \\
\hline $\mathrm{H} 2$ & $\begin{array}{c}\text { Financial Risk - } \\
\text { > Intention }\end{array}$ & 0.188 & 0.013 & 2.220 & Supported & 0.019 \\
\hline Intention & $\begin{array}{c}\text { Security Risk - } \\
\text { > Intention }\end{array}$ & 0.197 & 0.288 & 0.558 & Unsupported & 0.001 \\
\hline
\end{tabular}




\begin{tabular}{ccccccc}
\hline $\mathrm{H} 4$ & $\begin{array}{c}\text { Operational } \\
\text { Risk -> } \\
\text { Intention }\end{array}$ & 0.047 & 0.005 & 2.591 & Supported & 0.021 \\
\hline
\end{tabular}

\section{Discussion}

The results show that financial risk, legal risk and operational risk are negatively correlated to intention to use FinTech. In other words, financial, legal and operational risks are barriers to Malaysians using FinTech. Among these three risk factors, operational risk $(B=0.197)$ is the strongest, followed by legal risk $(\mathrm{B}=0.188)$ and financial risk $(\mathrm{B}=0.184)$.

Operational risk is the internal problem that can occur when people use FinTech. Operation risk is also related to risk in transaction error, the risk of incomplete transaction due to system failure, the risk of lack of operational skill and immediate response to the system problems. The results show that operational risk has a significant negative impact on consumers' intention to use FinTech. Therefore, when there are frequent transaction errors, incomplete or unsuccessful transactions, or lack of operational skill and responses on problems caused by FinTech is high, then intend to use FinTech is lower.

The legal risk in FinTech context it refers to the legal status of FinTech, which is unclear, and there is no universal regulation. Legal risk includes risks related to customers' data and privacy, as well as the safeguards of the financial system. In terms of legal risks, relevant FinTech security and regulatory issues are guaranteed before they are implemented. The results show that as legal risks increase, consumers are less intention to use FinTech. The result is consistent with the findings of the study by Ryu (2018), which consumers concerned about the legal risks and therefore reluctant to use FinTech. Notably, if the FinTech business is any business or activities includes regulated or licenced activities in Malaysia, the regulatory and legal requirements for conducting such business or activities must be complied with per applicable Malaysian laws (Siaw \& Kow, 2019). Under the control of Bank Negara Malaysia (BNM), all FinTech activities are regulated under the Financial Services Act 2013 (FSA). BNM also launched the sandbox Framework for financial technology regulation (BNM Framework) to reshape the development and innovation of FinTech (Siaw \& Kow, 2019). However, the result of this study indicates that Malaysian consumers still lack awareness and confidence in the legal protection of FinTech by BNM.

This study found that financial risk has a significant negative impact on the intention to use FinTech. This study is consistent with the study of Ryu (2018). This conclusion indicates that consumers' intention to use FinTech is influenced by potential financial losses, such as financial fraud, the collapse of trading frameworks, and misrepresentation of monetary. Notably, financial risk is not the most significant factor in determining the intention to use of FinTech. One possible explanation is that consumers are more concern with the operational and legal issues when deciding their intention to use FinTech. Financial transactions will be protected when FinTech services providers can provide sound system and services and have comprehensive legal protection.

Interestingly, this study found that the security risk was not significant $(\mathrm{B}=0.047, \mathrm{p}$-value $=0.288)$. However, this finding is consistent with the findings of a study in which the perception of electronic payment by Malaysian consumers has no relationship with perceived security (Teoh, Chong, Lin, \& Chua, 2013). It can be proved by implementing strict security measures such as encryption, digital signature and two-step verification in network data transmission and FinTech application, and removing the perceived security risk as an important obstacle to the intention to use FinTech.

Figure 1: Outcome of the Structural Model Examination (Coefficient and p-value) 


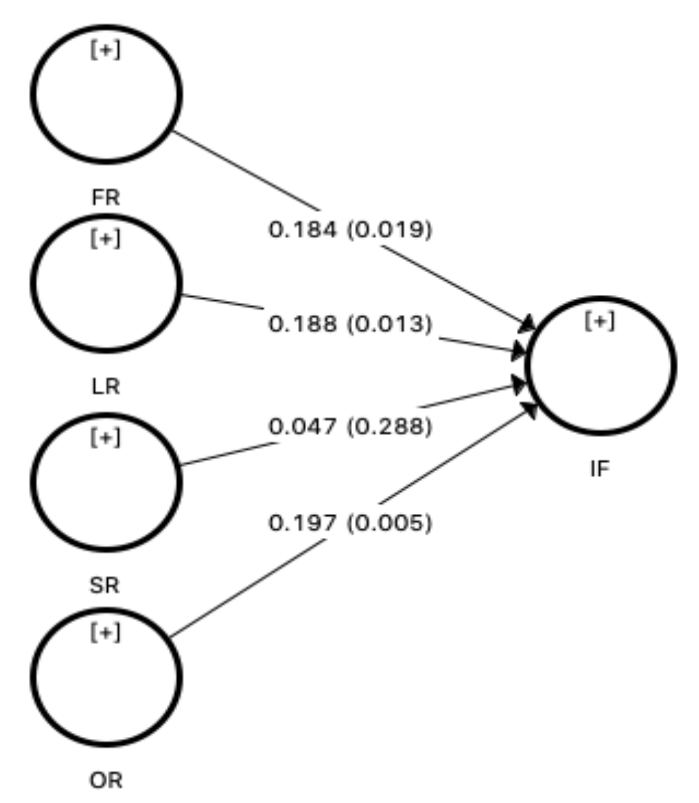

The above findings explain the risk factors in applying modern IT technologies that change the preconditions for managerial and accounting, modify the ways of sharing, aggregation and distribution of information, leading to the emergence of a new accounting infrastructure. Changes in the IT sector can significantly modify the postulates and categories of an accounting system. Although, the application of innovative advances in the field of IT in accounting provides the opportunity to process large arrays of information in the shortest possible time., the risk factors need to be understood as well.

\section{Limitations and Future Study}

The study is limited and only focus on the perceived risk factors. It investigates the impact of the perceived risk factors on the Malaysian consumers' intention to use FinTech. Future research should expand and discuss the both perceived benefits factors and perceived risks factors in explaining the use intention of FinTech in Malaysia. Another limitation of this study includes abandoning the actual use of FinTech variables. It is recommended that future researchers conduct further studies to examine the actual use of FinTech in their research framework.

\section{Conclusion}

The dimension of perceived risk factors has been studied extensively in various fields. This study is intended to provide additional insights into the literature on the use of consumer FinTech systems, particularly to help practitioners better conceptualise, reduce risk barriers and helping them prepare for the disruption of FinTech. The results of this study are consistent with the results of previous studies, in which financial risk, legal risk and operational risk are important factors hindering the intention to use FinTech. The result shows that security risk is no statistically significant impact on the FinTech use intention. Lastly, it is necessary to pay attention to operational skills and system functional performance when providing services, because the inadequacy or failure of financial services operation will lead to consumer dissatisfaction and trust, which will lead to barriers to the use of FinTech.

\section{Reference}

Abramova, S., \& Böhme, R. (2016). Perceived benefit and risk as multidimensional determinants of bitcoin use: A quantitative exploratory study. In 2016 International Conference on Information Systems, ICIS 2016.

Ajzen, I., \& Fishbein, M. (1977). Attitude-behavior relations: A theoretical analysis and review of empirical research. Psychological Bulletin, 84(5), 888-918. https://doi.org/10.1037/00332909.84.5.888

Al-Mamary, Y. H., Al-nashmi, M., Hassan, Y. A. G., \& Shamsuddin, A. (2016). A Critical Review of 
Models and Theories in Field of Individual Acceptance of Technology. International Journal of Hybrid Information Technology, 9(6), 143-158. https://doi.org/10.14257/ijhit.2016.9.6.13

Arner, D., Barberis, J., \& Buckley, R. (2015). The Evolution of Fintech: A New Post-Crisis Paradigm?, 2015. Retrieved from http://weekly.cnbnews.com/news/article.html?no=124000

Barakat, A., \& Hussainey, K. (2013). Bank governance, regulation, supervision, and risk reporting: Evidence from operational risk disclosures in European banks. International Review of Financial Analysis, 30, 254-273. https://doi.org/10.1016/j.irfa.2013.07.002

Chan, R. (2015). Asian regulators seek fintech balance. Retrieved 7 October 2019, from https://www.financeasia.com/article/asian-regulators-seek-fintech-balance/401588

Cohen, J. (1988). Statistical Power Analysis for the Behavioral Sciences. Physical Review B Condensed Matter and Materials Physics (2nd ed., Vol. 60). Lawrence Etlbaum Associates.

EY. (2019). Global FinTech Adoption Index 2019, 44. Retrieved from https://assets.ey.com/content/dam/ey-sites/ey-com/en_gl/topics/banking-and-capital-markets/eyglobal-fintech-adoption-index.pdf

Fornell, C., \& Larcker, D. F. (1981). Evaluating Structural Equation Models with Unobservable Variables and Measurement Error. Journal of Marketing Research, 18(1), 39-50.

Forsythe, S., Liu, C., Shannon, D., \& Gardner, L. C. (2006). Development of a scale to measure the perceived benefits and risks of online shopping. Journal of Interactive Marketing, 20(2), 55-75. https://doi.org/10.1002/dir.20061

Hu, Z., Ding, S., Li, S., Chen, L., \& Yang, S. (2019). Adoption intention of fintech services for bank users: An empirical examination with an extended technology acceptance model. Symmetry, 11(3). https://doi.org/10.3390/sym11030340

Kim, D. J., Ferrin, D. L., \& Rao, H. R. (2008). A trust-based consumer decision-making model in electronic commerce: The role of trust, perceived risk, and their antecedents. Decision Support Systems, 44(2), 544-564. https://doi.org/10.1016/j.dss.2007.07.001

Lee, D. K. C., \& Teo, E. G. S. (2015). Emergence of Fintech and the Lasic Principles. SSRN Electronic Journal. https://doi.org/10.2139/ssrn.2668049

Luo, X., Li, H., Zhang, J., \& Shim, J. P. (2010). Examining multi-dimensional trust and multi-faceted risk in initial acceptance of emerging technologies: An empirical study of mobile banking services. Decision Support Systems, 49(2), 222-234. https://doi.org/10.1016/j.dss.2010.02.008

Lwin, M., Wirtz, J., \& Williams, J. D. (2007). Consumer online privacy concerns and responses: A power-responsibility equilibrium perspective. Journal of the Academy of Marketing Science, 35(4), 572-585. https://doi.org/10.1007/s11747-006-0003-3

Mitchell, V.-W., \& Nygaard, A. (1999). Consumer perceived risk: Conceptualisations and models. European Journal of Marketing, 33(1-2), 163-195. https://doi.org/10.1108/03090569910249229

Padmanaban, P., \& Soo, H. K. Y. (2016). Catching the Fintech Wave A survey on FinTech in Malaysia. Retrieved from https://www.pwc.com/my/en/assets/publications/2016-pwc-aicb-catching-thefintech-wave.pdf

Palacios, J. G., Kaspereit, M., \& Kienle, A. (2011). Integrated Simulated Moving Bed Processes for Production of Single Enantiomers. Chemical Engineering and Technology, 34(5), 688-698. https://doi.org/10.1002/ceat.201000522

Quintal, V., Lee, J., \& Soutar, G. (2006). Attitudes Towards Risk and Uncertainty: Suggested Scales Vanessa Quintal, Curtin University of Technology Julie Lee, Geoff Soutar, University of Western Australia. In Proceedings of the Australian and New Zealand Marketing Academy.

Rich, S. U. (2014). Making-The of, 1(4), 32-39.

Ryu, H.-S. (2018). Understanding Benefit and Risk Framework of Fintech Adoption: Comparison of Early Adopters and Late Adopters. In Proceedings of the 51st Hawaii International Conference on System Sciences. Hawaii International Conference on System Sciences. https://doi.org/10.24251/hicss.2018.486

Ryu, H. S. (2018). What makes users willing or hesitant to use Fintech?: the moderating effect of user type. Industrial Management and Data Systems. https://doi.org/10.1108/IMDS-07-2017-0325

Siaw, T., \& Kow, C. (2019). Malysia: Fintech 2019. Retrieved 6 October 2019, from 
https://iclg.com/practice-areas/fintech-laws-and-regulations/malaysia

Sweeney, D. (2017). What Does FinTech Mean for SMBs. Retrieved 7 October 2019, from https://www.business.com/articles/what-is-fintech-and-what-does-it-mean-for-small-businesses/

Teoh, W. M. Y., Chong, S. C., Lin, B., \& Chua, J. W. (2013). Factors affecting consumers' perception of electronic payment: An empirical analysis. Internet Research, 23(4), 465-485. https://doi.org/10.1108/IntR-09-2012-0199

Zavolokina, L., Dolata, M., \& Schwabe, G. (2016). FinTech - What's in a name? Thirty Seventh International Conference on Information Systems. https://doi.org/10.5167/uzh-126806 